\title{
Design and Analysis of Double Truncated Circular Patch for Ultrawideband Applications
}

\author{
Anjaneyulu Katuru ${ }^{1 *}$, Venkata Narayana $\mathrm{Y}^{2}$, Ravindranadh Jammalamadugu ${ }^{3}$, and Sumalatha Kadire ${ }^{4}$ \\ ${ }^{1}$ Department of ECE, Narasaraopeta Engineering College, Narasaraopet, AP, India \\ ${ }^{2}$ Department of ECE, Tirumala Engineering College, Jonnalagadda, Narasaraopet, AP, India \\ ${ }^{3}$ Department of ECE, RVR \& JC College of Engineering, Guntur, AP, India \\ ${ }^{4}$ Department of ECE, Malla Reddy Engineering College for Women, Secunderabad, Telangana, India \\ *Corresponding author E-mail: anjikaturu@gmail.com
}

\begin{abstract}
In this article, a double truncated circular patch (DTCP) with a defective ground structure (DGS) and having a microstrip line feed was addressed. The proposed antenna is designed to operate from 2.75 to $14 \mathrm{GHz}$ (11.25 GHz spectrum). The desired antenna is printed on FR-4 substrate. A (PGP) partial ground plane with a notch was printed on the backside of the substrate to approach the ultrawideband (UWB-3.1-10.6 GHz) characteristics. The patch was truncated on the top and left sides of the circular patch to attain the characterization of UWB. The performance and characteristics of this antenna can be evaluated through reflection coefficient $\left(\mathrm{S}_{11}\right)$, voltage standing wave ratio (VSWR), and radiation patterns and gain. The performance of this antenna is analyzed by using simulated results.
\end{abstract}

Keywords: Double truncated circular patch, defective ground structure, UWB.

\section{Introduction}

Wireless communication, in the recent years, is becoming more popular. Antennas are an essential part of any radio (wireless) communication systems. Ultra-wideband antenna is a radio technology that can be used at very low energy levels for short range, high bandwidth communications by using a large portion of radio spectrum which has been extensively used in wide variety of applications. After allocation of the frequency band from $3.1 \mathrm{GHz}$ to $10.6 \mathrm{GHz}$ for commercial utilization of ultra-wideband systems by the Federal Communication Commission (FCC) [1], UWB systems have received a phenomenal gravitation in wireless communication. Designing of an antenna for UWB communications is a challenging task because it has to satisfy some requirements such as ultra-wide bandwidth, constant group delay, constant gain, high radiation efficiency, Omni-directional radiation pattern, low profile, ease of fabrication and so forth [2]. Some of the wireless communication systems such as WiMAX (Worldwide Interoperability for Microwave Access) IEEE 802.11a Wireless Local Area Network (WLAN) bands in USA and High Performance Radio Local Area Network/2 (HIPERLAN/2) bands in Europe exist in UWB range. Hence, the potential interference from these bands should be avoided for better performance of UWB antenna. Various UWB antennas with band-notched techniques have been proposed such as cutting arc-slot in patch [3], inserting a slit in patch [4], embedding a tuning stub in slot [5]. The UWB characteristics can be obtained by using defected ground structure and radiation efficiency can be improved by placing impedance transformer in the feed line [6]. The UWB characteristics can also be obtained by cutting square slots on the patch and truncating the ground plane with notch [7].

In this paper, DTCP UWB antenna was designed and a defected ground plane and truncation of the patch is proposed to attain the UWB characteristics and to increase the impedance bandwidth.

\section{Structure of antenna}

The configuration of the proposed antenna is shown in Figure 1. It is designed on FR-4 substrate with dimensions (W $\times \mathrm{L} \times \mathrm{H}) \mathrm{mm}^{3}$ and having $\varepsilon_{\mathrm{r}}=4.3, \mu=1$ and $\tan \delta=0.025$. The antenna is fed by a microstripline having dimensions ( $\mathrm{wf} \times \mathrm{lf}$ ) $\mathrm{mm}^{2}$ with the input impedance of $50 \mathrm{ohm}$. The proposed antenna is constituted by truncating the conventional circularl patch along $\mathrm{x}$ - and $\mathrm{y}$-direction along with partial defective ground plane.

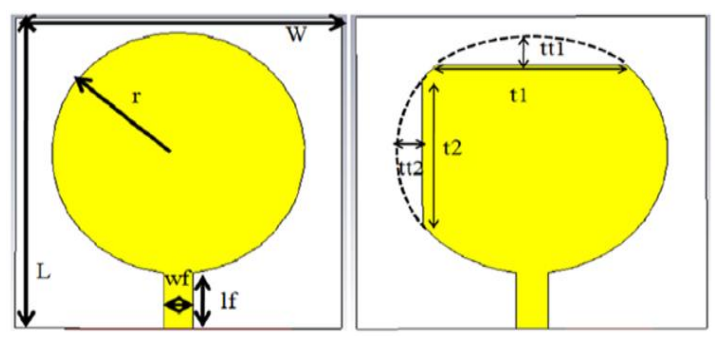

(a)

(b)

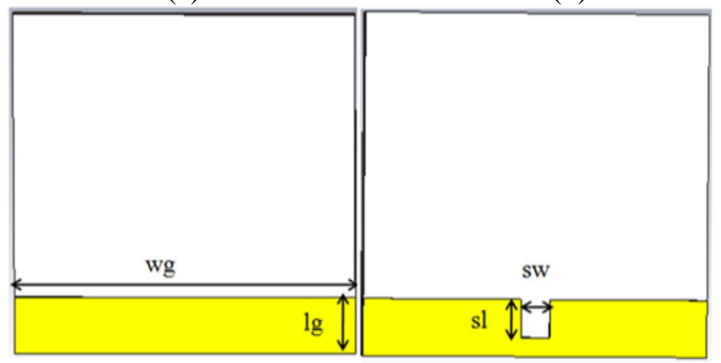

(c)

(d)

Fig.1. (a) Conventional circular patch (CCP) (b) DTCP (c) PGP (d) Defected ground structure (DGS) 
The patch is truncated along $\mathrm{x}$-direction with $\mathrm{t} 1=20 \mathrm{~mm}$ and $\mathrm{y}$-direction with $\mathrm{t} 2=14 \mathrm{~mm}$ to achieve UWB characteristics. A partial ground plane is printed on the back side of the substrate and a notch is cut on the ground plane with dimensions ( $\mathrm{sw} \times$ sl) $\mathrm{mm}^{2}$ to improve the UWB characteristics. The dimensions of the proposed antenna are tabulated in Table 1. The physical parameters of the antenna are optimized and simulated by using CST (Computer Simulation Technology) Microwave Studio. The physical parameters of the patch are represented as width of the substrate $(\mathrm{W})$, length of the substrate (L), height of the substrate $(\mathrm{H})$, radius of the circular patch $(\mathrm{r})$, width of the feedline wf), length of the feedline (lf), width of the ground (wg), length of the ground (lg), thickness of the patch and ground (tp), truncation along $\mathrm{x}$ - direction (t1), truncation along $y$ - direction (t2), maximum length from circumference of patch to $\mathrm{x}$-direction of truncation (tt1), maximum length from circumference of patch to $y$-direction of truncation (tt2), slot width (sw), and slot length (sl).

Table 1: Antenna dimensions (all dimensions are in $\mathrm{mm}$ )

\begin{tabular}{|l|l|l|l|}
\hline Parameter & Value $(\mathrm{mm})$ & Parameter & Value $(\mathrm{mm})$ \\
\hline $\mathrm{W}$ & 36 & $\mathrm{tp}$ & 0.1 \\
\hline $\mathrm{L}$ & 36 & $\mathrm{t} 1$ & 20 \\
\hline $\mathrm{H}$ & 1.6 & $\mathrm{t} 2$ & 14 \\
\hline $\mathrm{r}$ & 14 & $\mathrm{tt} 1$ & 4 \\
\hline wf & 3.2 & $\mathrm{tt} 2$ & 3 \\
\hline lf & 6.6 & $\mathrm{sw}$ & 3 \\
\hline wg & 36 & $\mathrm{sl}$ & 4 \\
\hline
\end{tabular}

\section{Antenna design, results, and analysis}

\subsection{Step 1: Circular patch and partial ground plane}

In step 1, a circular patch with a partial ground plane as shown in Figure 1 (a) and (c) is designed and simulated by using CST microwave studio. The simulation results of reflection coefficient and VSWR verses frequency are shown in Figure 2 (a) and (b), which shows a hump above $-10 \mathrm{~dB}$ between the frequencies $5.45 \mathrm{GHz}$ and $7.2 \mathrm{GHz}$. In this case, the curve violates the UWB characteristics. Here the maximum value of hump is at $-6.24 \mathrm{~dB}$ at $6.3 \mathrm{GHz}$ and VSWR $>2$, that is shown in Figure 2.

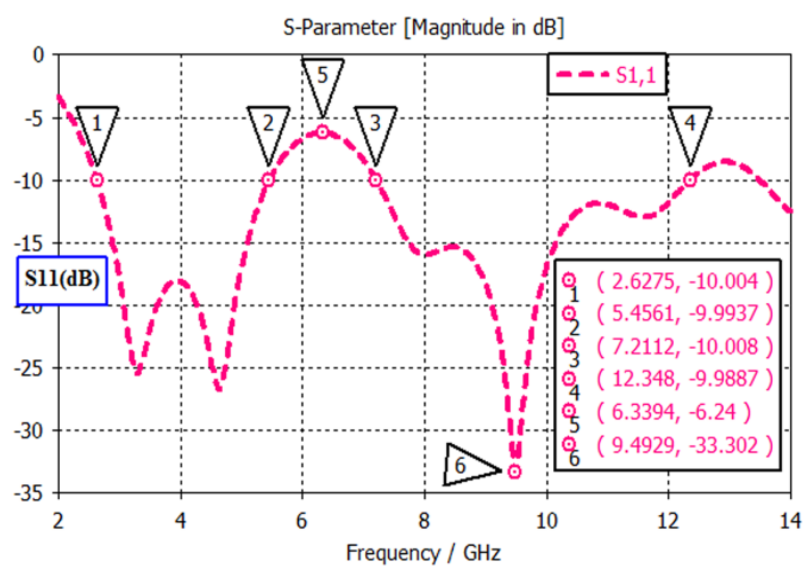

(a)

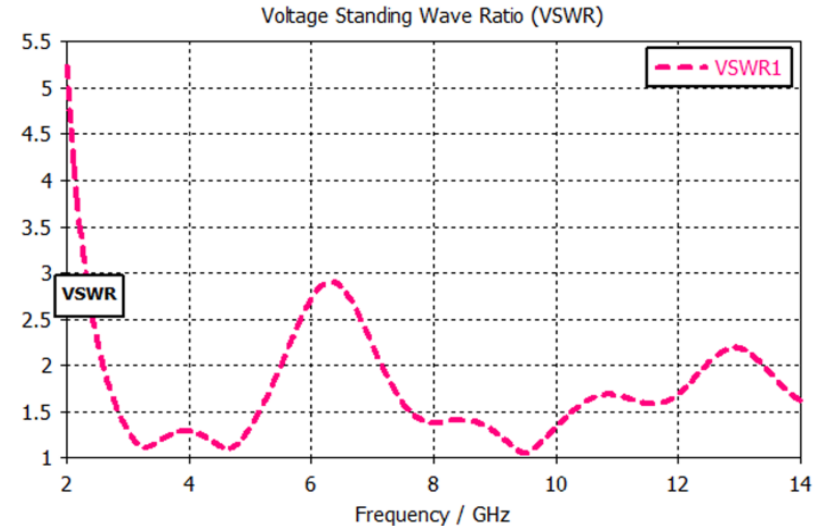

(b)

Fig.2. (a) Return loss \& (b) VSWR of conventional circular patch (CCP).

\subsection{Step 2: Circular patch with defected ground structure}

In step 2, the circular patch was not modified, but the ground plane was etched with the slot to improve the UWB characteristics and hump is shifted down to a value $-9.09 \mathrm{~dB}$ from $-6.23 \mathrm{~dB}$. In this case $S_{11}>-10 \mathrm{~dB}$ and VSWR $>2$, that are shown in figures Figure 3 (a) \& (b). In this case also UWB characteristics are not achieved.

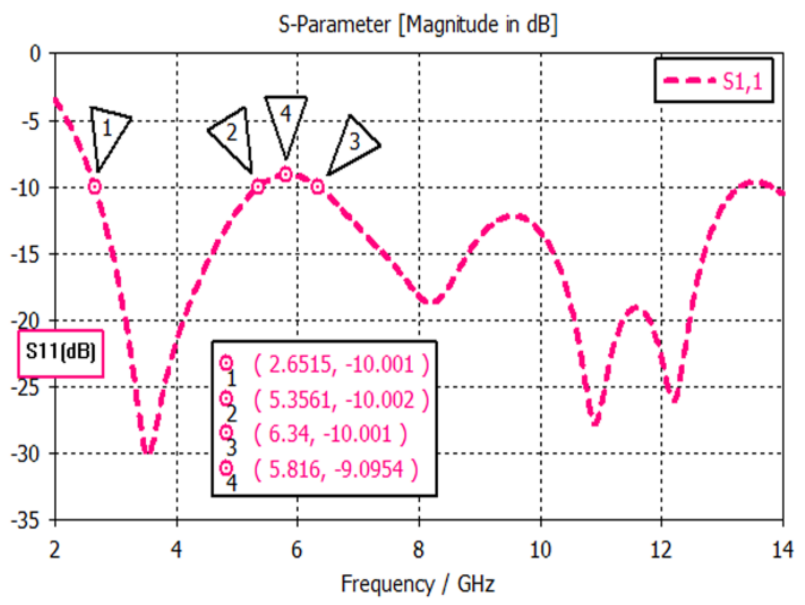

(a)

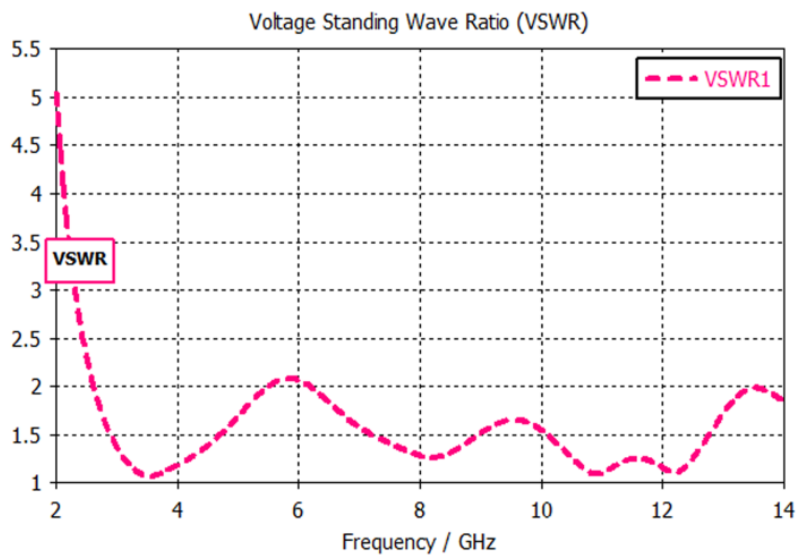

(b)

Fig.3. (a) Reflection coefficient (b) VSWR of CCP with defected ground structure. 


\subsection{Step 3: Double Truncated Circular Patch}

In this case the antenna is truncated on top and left side from the circumference to inward of the patch with $\mathrm{tt} 1=4 \mathrm{~mm} \& \mathrm{tt} 2=$ $3 \mathrm{~mm}$ to attain the UWB characteristics. In this case $\mathrm{S}_{11}<-10 \mathrm{~dB}$ and $\operatorname{VSWR}<2$, which satisfied the ultrawideband characterization and are shown in Figure 4 (a) and (b).

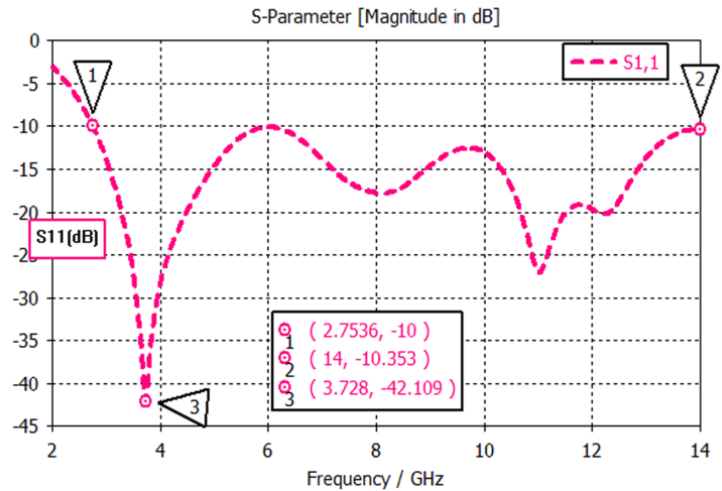

(a)

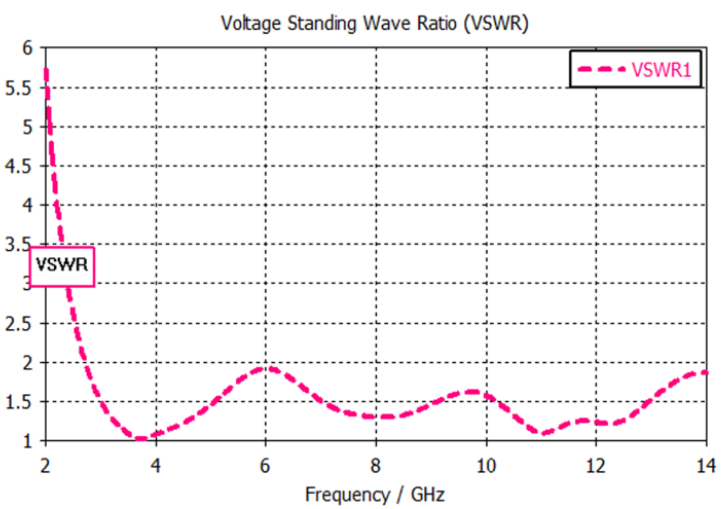

(b)

Fig.4. (a) $S_{11}$ (Return loss) (b) VSWR of DTCP.

\section{Antenna radiation patterns}

The simulated 3D (Figure 5) and polar (Figure 6) gain patterns for DTCP antenna at different frequencies such as 3.2, 6.2, 9.5 and $11.2 \mathrm{GHz}$ are observed. It was identified that the patterns are almost nearly Omni-directional.

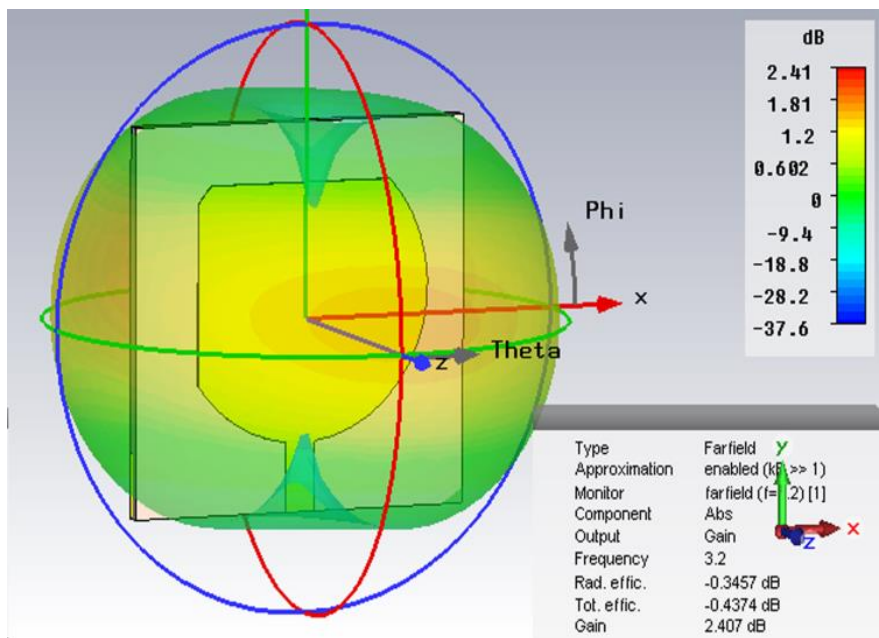

(a)

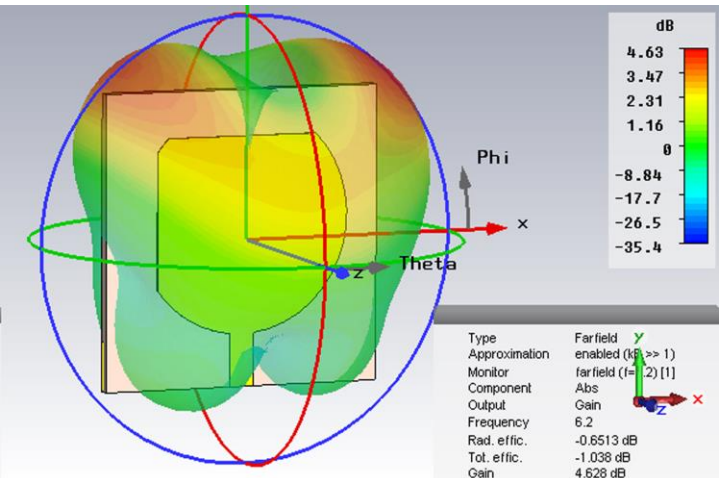

(b)

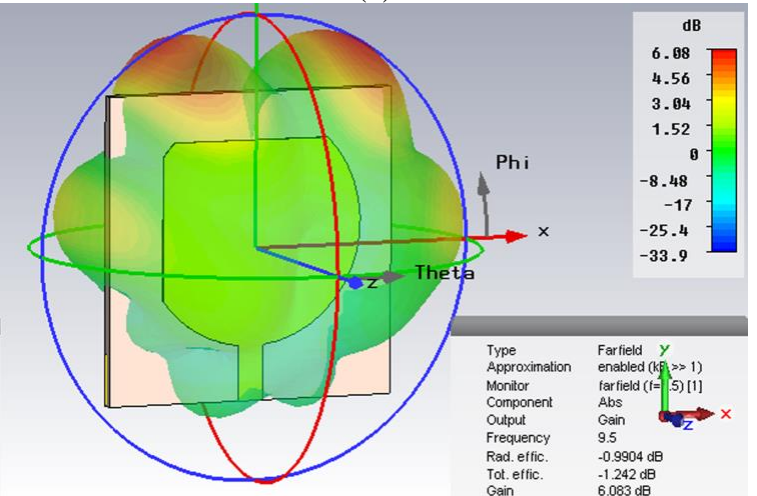

(c)

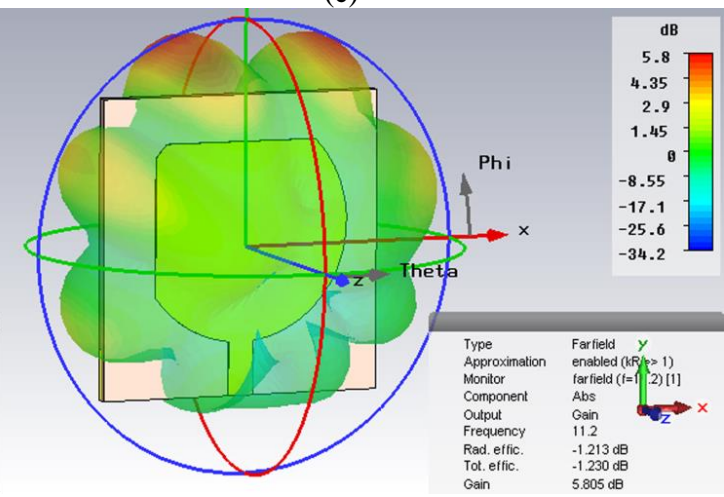

(d)

Fig.5. 3-dimensional radiation patterns at (a) 3.2 (b) 6.2 (c) 9.5 (d) $11.2 \mathrm{GHz}$ frequencies.

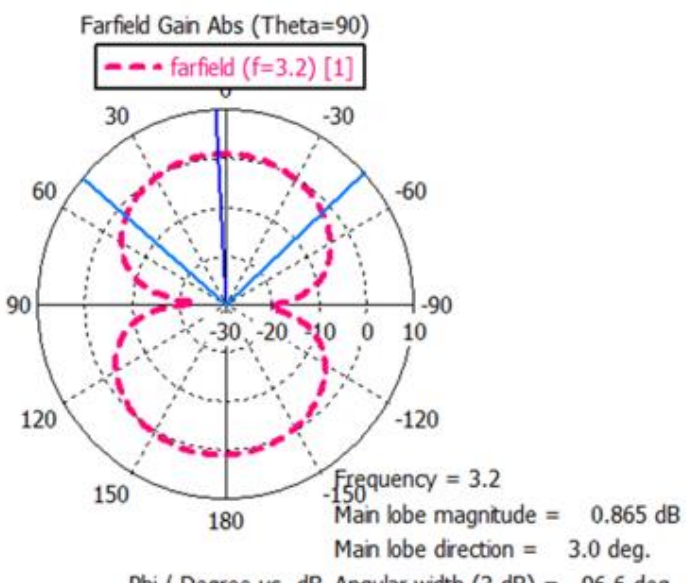

(a) 


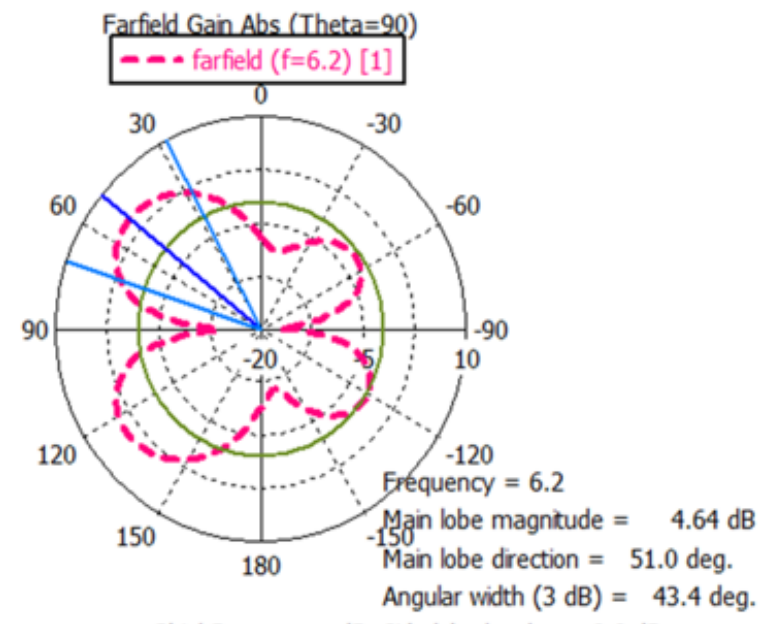

Phi / Degree vs. $d B$ Side lobe level $=-6.6 \mathrm{~dB}$

(b)

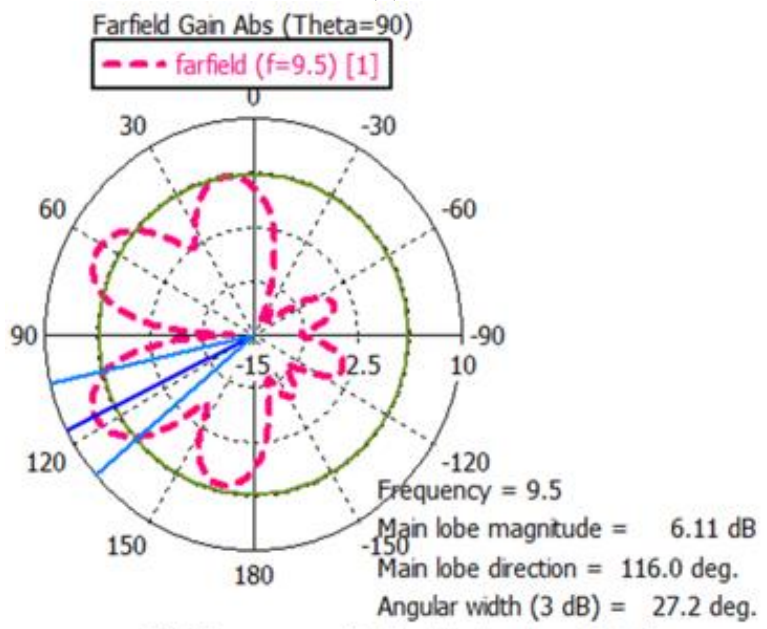

Phi / Degree vs. $\mathrm{dB}$ Side lobe level $=-2.6 \mathrm{~dB}$

(c)

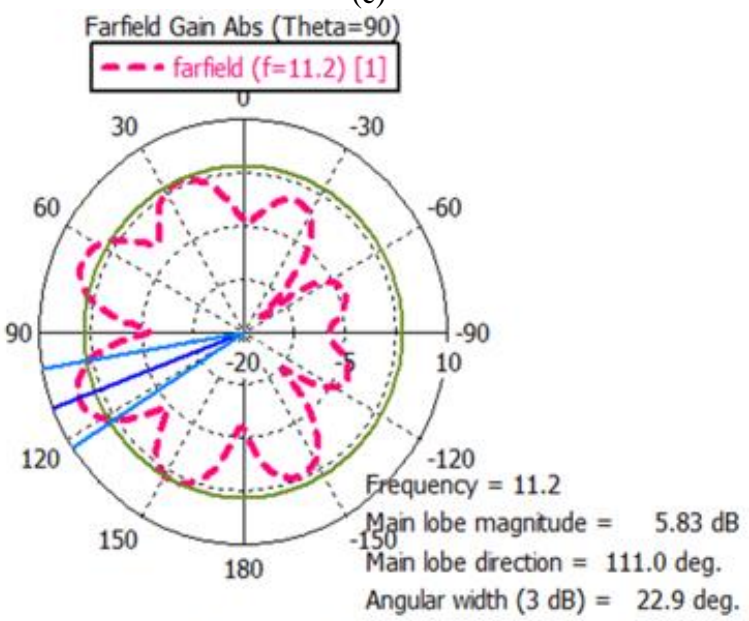

Phi / Degree vs. $\mathrm{dB}$ Side lobe level $=-2.4 \mathrm{~dB}$

(d)

Fig.6. Polar patterns at (a) 3.2 (b) 6.2 (c) 9.5 (d) $11.2 \mathrm{GHz}$ frequencies

The simulated gain values at these frequencies are tabulated in Table 2 . The antenna radiates the maximum radiation efficiency of $92.3 \%$ at $3.2 \mathrm{GHz}$ that is shown in Figure 7. The peak gain of $6.3 \mathrm{dBi}$ is observed at $8 \mathrm{GHz}$, which is depicted in Figure 8.

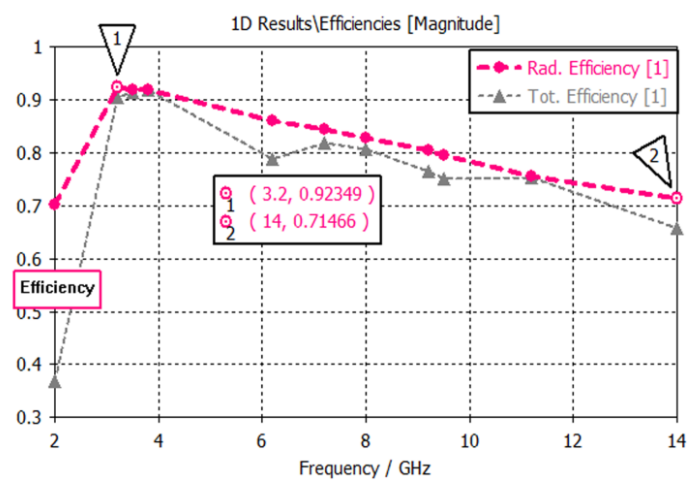

Fig.7. Radiation efficiency of required antenna.

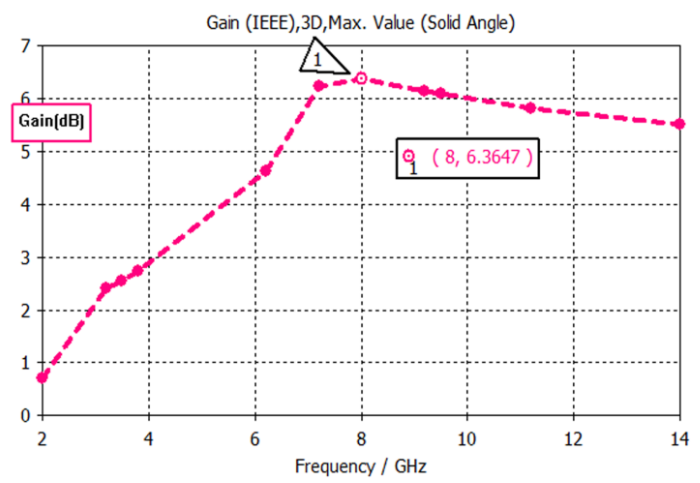

Fig.8. Gain vs. frequency plot.

Table 2: Antenna Gain at various frequencies

\begin{tabular}{|l|l|}
\hline Frequency $(\mathbf{G H z})$ & Gain $(\mathbf{d B i})$ \\
\hline 3.2 & 2.41 \\
\hline 6.2 & 4.63 \\
\hline 9.5 & 6.08 \\
\hline 11.2 & 5.8 \\
\hline
\end{tabular}

\section{Conclusion}

The proposed double truncated circular patch (DTCP) with defective ground structure (DGS) for UWB applications was designed and analyzed using MS-CST. A relatively 11.25 $\mathrm{GHz}(2.75$ to $14 \mathrm{GHz})$ wide spectrum was obtained. The antenna provides satisfactory omni-directional radiation patterns. This antenna yields $\mathrm{S} 11<-10 \mathrm{~dB}$ and VSWR $<2$. These UWB characteristics was obtained by modifying the circular patch with DGS. The simulation results show that the proposed antenna is suitable for UWB applications.

\section{References}

[1] Federal Communication Commission, First report and order, revision of part 15 of commission's rules regarding UWB Trans. systems, F.C.C, 02-48, 2002.

[2] D. Cheng, Compact Ultra Wideband Microstrip Resonating Antenna. US patent $7872606,2011$.

[3] K. Yin and J. P. Xu, Compact ultra-wideband antenna with dual band stop characteristics, Electronics Letters, vol. 44, pp. 453454, 2008.

[4] M. Abdollahv, G. R. Dadashzadesh, and H. Ebrahimian, Compact band rejection printed monopole antenna for UWB application, IEICE Electronics Express, vol.8, no.7, pp. 423-428, 2011.

[5] C. Y. Hong, C. W. Ling, I. Y. Tarn, and S .J. Chung, Design of a planar ultra-wideband antenna with a new band notch structure, IEEE Transactions on Antennas and Propagation, vol. 55, no.12, pp. 3391-3397, 2007. 
[6] K. Anjaneyulu, and A. Sudhakar, Design and analysis of matched microstrip line feed antenna for ultra wideband applications, International Journal on Communications Antennas and Propagation, vol. 6, no. 6, pp. 369-374, 2016.

[7] M. Moosazadesh, Ch. Ghobadi, and M. Dousti, Small monopole antenna with checkered-shaped patch for UWB applications, IEEE Antennas and Wireless Propagation Letters, vol. 9, pp. 1014-1017, 2010

\section{Biography of the authors}

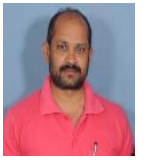

Anjaneyulu Katuru, was born in 1976 . He received B.Tech. (E.C.E) degree from R.V.R \& J.C. College of Engg. in 2005, ANU, Guntur(Dist), A.P. He received M. Tech. degree in 2008, in the area of Communication and Signal Processing from B.E.C, Bapatla, Guntur (Dist), A.P. His Ph.D. was awarded in 2019 in the area of "ANTENNAS". He qualified UGC NET in the field of ELECTRONIC SCIENCE in 2013. He is working as a Professor in the Dept. of ECE in Narasaraopeta Engineering College (Autonomous). He has teaching experience of 13 years. He has LIFE membership of ISTE. His research interests include Ultra-Wideband (UWB) antennas, broadband antennas, antenna arrays and microwave devices.

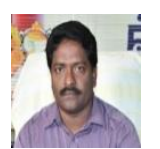

Y.V.Narayana completed his Ph.D. in the field of "Antenna arrays", in Andhra University, Visakhapatnam. He was HOD with an experience of 11 years in teaching. At present, he is working as a PRINCIPAL in Tirumala Engineering College since 2008. He is the life member in so many professional bodies like ISTE, IEEE etc. He published so many international journals and paricipated inseveral national and international conferences.He is an excellent academecian. His areas of interest are antennas, microwaves,image processing.

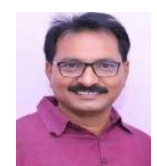

Ravindranadh Jammalamadugu, studied B.Tech. (E.C.E) from S.R.K.R Engineering College, Bhimavaram. (Andhra University, Vishakapatanam), Andhra Pradesh in 1993. .He received M. TECH in the area of Digital System \& Computer Electronics in 2006 from Sreenidhi Institute of Science Technology, JNTUH, Hyderabad, Telangana., His Ph.D. was awarded in 2018 in the area of "ANTENNAS" from JNTUK, Kakinada,AP India. He is working as a Professor in the Dept. of ECE in RVR \& JC College of Engineering (Autonomous), Guntur, AP, India. He has teaching experience of 25 years. He has LIFE memberships of ISTE, IETE and IAENG. His research areas are microwave antennas and digital image processing.

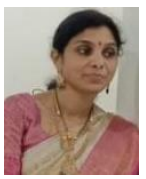

Sumalatha Kadire, working as an Associate Professor in Malla Reddy Engineering College for Women (Autonomous), Secunderabad, Telangana, India. She is pursuing Ph.D. degree in the area of ANTENNAS from GITAM Deemed to be University, Vizag, AP, India. She has 12 years of teaching experience. Her areas of interest are Antennas and Microwave devices. 